
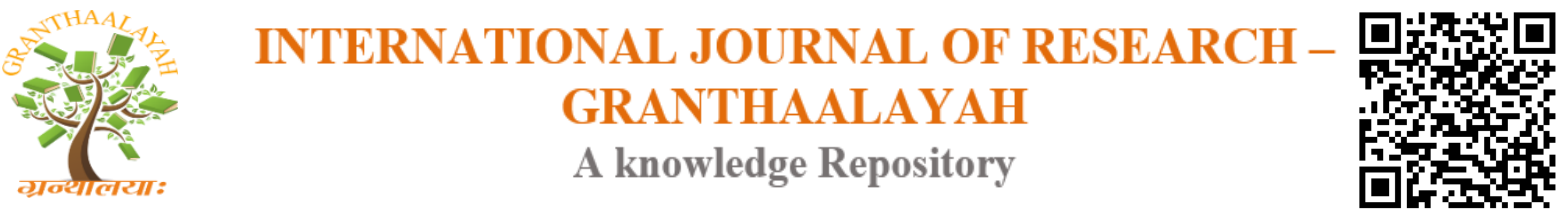

Science

\title{
DETECTION AND QUANTITATION OF RED COMPLEX BACTERIA IN SUBGINGIVAL PLAQUE BY USING FLUORESCENT IN SITU HYBRIDIZATION (FISH)
}

\author{
Dr. Kishore G. Bhat ${ }^{* 1}$, Dr Aradhana Chhatre ${ }^{2}$, Mr. Vijay M. Kumbar ${ }^{3}$, Mr. Manohar S. \\ Kugaji ${ }^{4}$, Mrs. Sanjeevani Patil ${ }^{5}$ \\ *1,2, 3, 4, 5 Maratha Mandal's Central Research Laboratory, Maratha Mandal's NGH Institute of \\ Dental Sciences \& Research Centre, Belgaum, Karanataka, India
}

\begin{abstract}
Motivation/Background: Red complex bacteria are proven periodontal pathogens. In dentistry, there is a need to identify and quantitate the organisms from the diseased sites quickly and reliably. Since culture requires several days, molecular methods are being used frequently to detect these bacteria. Among them, Fluorescent in situ hybridization (FISH) is rapid, sensitive and quantitative. An attempt is made here to evaluate the applicability of this technique as a diagnostic tool in periodontology.

Method: Subgingival plaque was collected from participants, fixed with paraformaldehyde and subjected to FISH. Fluorescently labeled oligonucleotide probes were used for hybridization. After the procedure, the fluorescently stained bacteria were identified and counted from the smear and quantitated using a simple grading.

Results: There was a significant difference in the prevalence and numbers of red complex bacteria in healthy and diseased subjects. A strong linear relationship existed between P. gingivalis, T. forsythia and T. denticola.

Conclusions: The procedure used in the study is simple, rapid and can be easily adaptable. It also has a high sensitivity and has the ability to detect a single bacterial cell. The method can be directly applied to the clinical samples and can be used as a rapid diagnostic tool in periodontics.
\end{abstract}

Keywords: Fish; P. Gingivalis; T. Denticola; T. Forsythia; Periodontitis.

Cite This Article: Dr. Kishore G. Bhat, Dr Aradhana Chhatre, Mr. Vijay M. Kumbar, Mr. Manohar S. Kugaji, and Mrs. Sanjeevani Patil. (2017). "DETECTION AND QUANTITATION OF RED COMPLEX BACTERIA IN SUBGINGIVAL PLAQUE BY USING FLUORESCENT IN SITU HYBRIDIZATION (FISH)." International Journal of Research - Granthaalayah, 5(11), 279-289. https://doi.org/10.29121/granthaalayah.v5.i11.2017.2354.

\section{Introduction}

Periodontal diseases are multifactorial infections elicited by a complex of bacterial species and the host immune response towards them, which may lead to destruction of periodontal structures 
including the tooth supporting tissues, alveolar bone and periodontal ligament [1]. The trigger for the initiation of the disease is the presence of complex microbial biofilm in the subgingival area that houses $>700$ bacterial species and phylotypes [2]. Socransky and colleagues have done extensive work on the oral microbial community and have catalogued them into different complexes that occur together and associated with the plaque of gingival health, gingivitis and periodontitis [3]. Among them, the "red complex" comprises three species that are known to be periodontal pathogens - Porphyromonas gingivalis, Tannerella forsythia and Treponema denticola. They are consistently found at sites of periodontal disease and are known to be involved in the initiation and progression of the disease. They are usually found together in plaque samples and appear to be nutritionally interdependent [4]. These periodontopathic bacteria are difficult to culture since they are strict anaerobes with complex growth requirements [5]. Hence various approaches have been used to identify organisms from oral niches without the requirement of laboratory cultivation. These methods include polymerase chain reaction, hybridization, whole sequence analysis and electrophoretic techniques [6].

Modern fluorescence microscopic techniques based on fluorogenic dyes are extremely popular for the study of cells and tissues. Among them, whole cell hybridization with fluorescently labelled rRNA targeted oligonucleotide probes allow detection of bacteria at single cell level and also help in their quantitation in complex microbial communities [7]. This method is popularly known as fluorescent in situ hybridization (FISH).

The aim of the present study was to visualize, identify and quantitate red complex bacteria from the subgingival plaque of healthy individuals and patients with chronic periodontitis using FISH and evaluate its applicability as a diagnostic tool in periodontology.

\section{Materials and Methods}

The present study was performed in the Central Research Laboratory of Maratha Mandal's NGH Institute of Dental Sciences, Belagavi. This investigation was part of a funded project from Rajiv Gandhi University of Health Sciences, Bengaluru on "A study of microbial diversity of subgingival plaque: comparison of Fluorescent in situ hybridization, denaturing gradient gel electrophoresis and dot blot hybridization". The study included 78 apparently healthy individuals and an equal number of patients with chronic periodontitis who attended the outpatient department of the institute. The participants were adult subjects between the age group of 18-55 years and belonged to both sexes. Ethical clearance was obtained from Institutional ethical committee. A written, informed consent was obtained from each participant before enrolling for the study.

The inclusion criteria for the healthy group were: no signs of gingival inflammation, absence of bleeding on probing, probing depth of $<3 \mathrm{~mm}$ and no clinical attachment loss. The criteria for selecting chronic periodontitis patients were: the presence of gingival inflammation, presence of bleeding on probing, probing depth of $>5 \mathrm{~mm}$ and clinical attachment loss of $>3 \mathrm{~mm}$. The exclusion criteria for both the groups were: patients with diabetes or any other systemic illness, tobacco habitués, patients on any type of medication, pregnant women, lactating mothers and patients who had undergone periodontal treatment and/or antimicrobial therapy during the last three months and subjects with $<20$ teeth. 
From each participant, after selection and isolation of the tooth, the supra-gingival plaque was stripped and the subgingival plaque was collected by curetting and transferred to vial containing Tris-EDTA buffer. Upon receipt in the laboratory, portion of the plaque was transferred to a vial containing ice-cold paraformaldehyde (4\%), fixed for 4 hours, washed three times with ice-cold phosphate buffered saline (PBS) and then resuspended in equal proportions of PBS and ethanol $(96 \%)$ and stored at $-20^{\circ} \mathrm{c}$ till use [8].

The probes used for targeting red complex bacteria were species specific and were complementary to $16 \mathrm{~s}$ rRNA of the respective organism. The sequences used for probe synthesis were adopted from probebase[http://www.probebase.net][9] (Table 1).

Table 1: Oligonucleotide probes used in this study

\begin{tabular}{|c|c|c|}
\hline Organism & $\begin{array}{c}\text { Probe sequence } \\
\mathbf{5} \mathbf{\prime}^{\prime},\end{array}$ & $\begin{array}{c}\text { Fluorescent } \\
\text { labeling }\end{array}$ \\
\hline P. gingivalis & CAA TAC TCG TAT CGC CCG TTA TTC & 5' FAM \\
T. forsythia & CGT ATC TCA TTT TAT TCC CCT GTA & 5' FAM \\
T. denticola & CAT GAC TAC CGT CAT CAA AGA AGC & 5'HEX \\
\hline
\end{tabular}

The probes for $\mathrm{P}$. gingivalis and $\mathrm{T}$. forsythia were labeled with fluorescent dye FAM and the probe for T. denticola was labeled with HEX dye on the 5' end (procured from Bioserve, USA). The procedure was optimized by testing the probe against standard strain of A. actinomycetemcommitans (ATCC 43718). We performed initial trials with different probe concentrations, hybridization temperatures and incubation timings for optimization of the protocol. The specificity of the probe was confirmed by testing against known strains of Prevotella intermedia, Treponema socransky, Aggregatibacter actinomycetemcomitans, Eiknella corrodens, Campylobacter rectus Actinomyces viscosus and Streptococcus mutans.

For preparation of slides, $10 \mu \mathrm{l}$ of the fixed sample was applied to gelatin coated slide, allowed to dry and was dehydrated by exposing the material to serial concentrations of ethanol. The slides were then dried at $46^{\circ} \mathrm{c}$ for 10 minutes and FISH was performed. Briefly, fresh hybridization buffer was prepared with $30 \%$ formamide concentration, and oligonucleotide probe was diluted in this buffer to achieve a concentration of 20 picomoles in $100 \mu 1$ of buffer and applied to the plaque on the slide. It was kept in a moist petri dish and incubated at $46^{\circ} \mathrm{c}$ for 2 hours. The hybridization buffer was then decanted and slides were washed in wash buffer at $46^{\circ} \mathrm{c}$ for 10 minutes, the slides were then washed with ice cold distilled water, quickly air dried and mounted with cover slip using dpx mountant. They were wrapped in aluminium foil and stored at -20c till studied under the microscope [8].

The demarcated area of the plaque material was studied using fluorescent microscope with 40X and 100X objectives. The red complex bacteria appear as brightly fluorescent coccobacilli / bacilli. They were counted and graded by using a simple formula devised by us: no bacteria seen - 0/negative, 1-10 bacilli/smear - occasional/ 0.5, 11-25/smear - 1+, 26-100/smear-2+,>100 bacteria/smear $-3+$, clumps of bacteria seen $-4+$. 
Statistical analysis: comparison between the healthy individuals and patients with chronic periodontitis was done using Mann-Whitney test. Spearman rank correlation coefficient was used to assess the linear relationships between the three red complex bacteria studied.

\section{Results and Discussions}

To analyse results, comparison of the prevalence as well as different concentrations of all the three bacteria in healthy individuals and patients with chronic periodontitis was done. The data revealed that $\mathrm{P}$. gingivalis had a high prevalence in both the groups almost $100 \%$. However, the bacterial load was low with $38(48.7 \%)$ and $32(41 \%)$ samples in healthy individuals showing either occasional or $<25$ bacteria / smear respectively. On the other hand, the load of P. gingivalis was quite high in patients group with 27(34.6\%) showing $>100$ bacilli / smear. This result was statistically significant ( $\mathrm{p}$ value $=<0.001$ ).
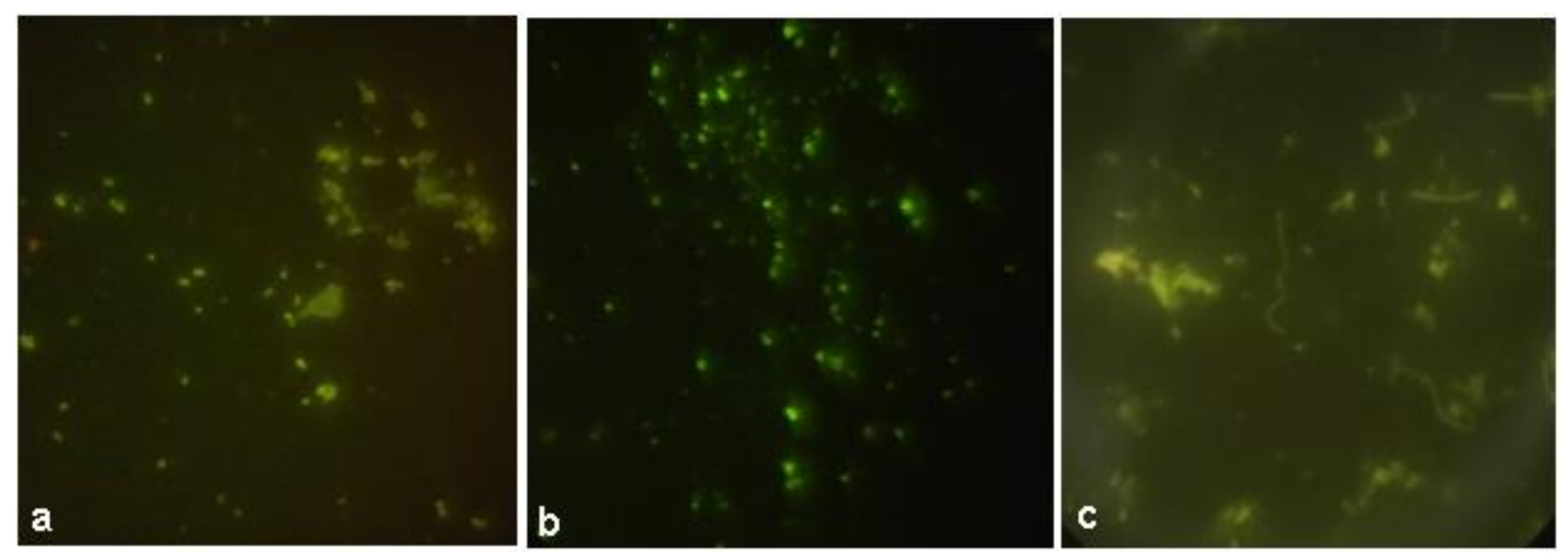

Figure 1: Fluorescence microscopy images of red complex bacteria. a) P.gingivalis labeled with

FAM fluorescent dye b) T.forsythia labeled with FAM fluorescent dye c) T.denticola labeled with HEX fluorescent dye.

The data for the other two bacteria was strikingly different (Fig. 2).

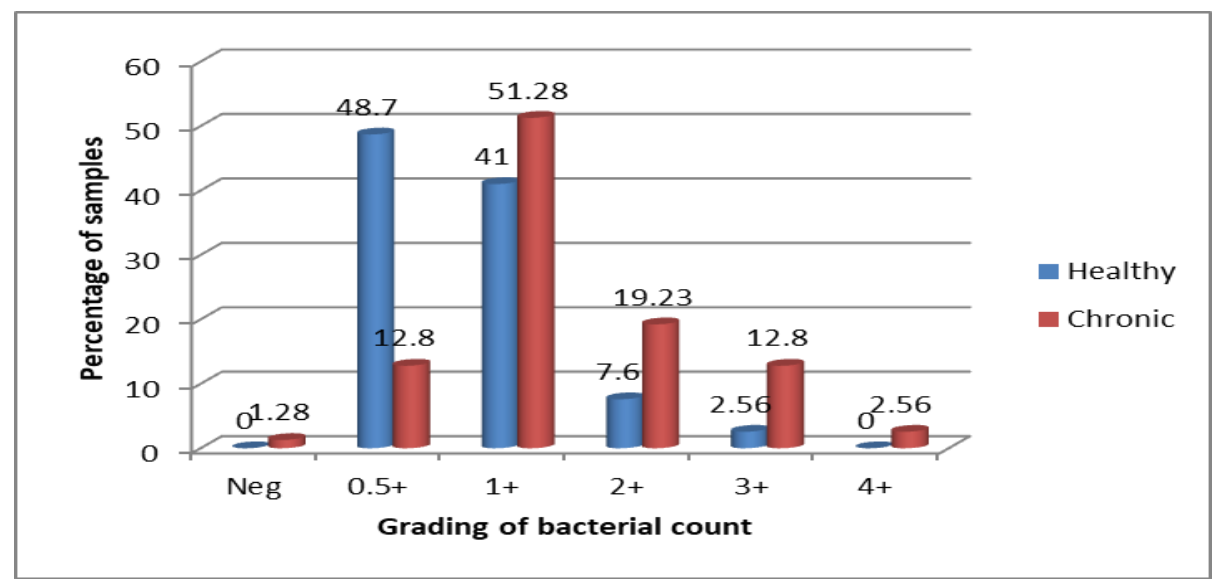

Figure 2: Chart showing Percentage distribution and bacterial count of P.gingivalis in healthy and chronic samples 
Tannerella forsythia was not seen in 36(46.1\%) of samples from healthy subjects and in almost all other samples, the concentrations were less. In contrast, only 15(19.23\%) of plaques from chronic periodontitis patients were negative with a fairly higher number of bacterial load in remaining samples. This difference also was statistically significant ( $p$ value $=0.002)($ Fig. 3 ).

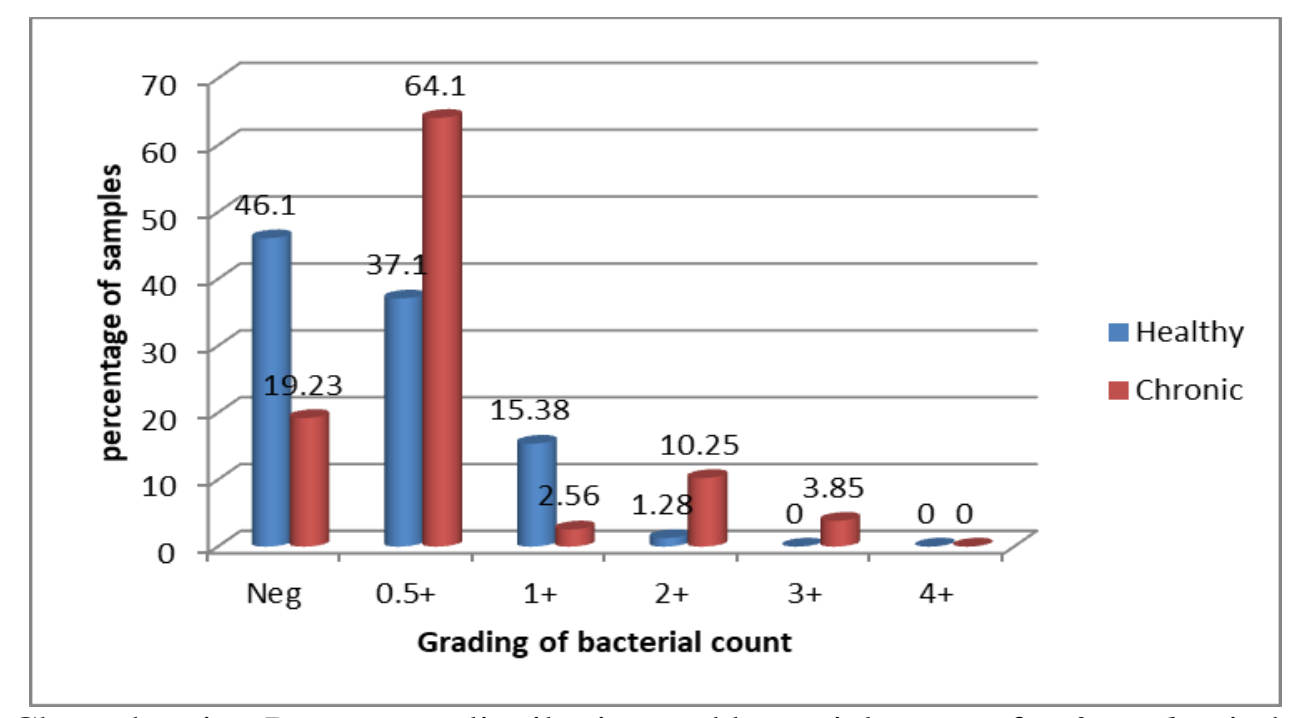

Figure 3: Chart showing Percentage distribution and bacterial count of T.forsythia in healthy and chronic samples

The distribution of T. denticola was almost similar to that of T. forsythia with $35(44.87 \%)$ and $12(15.38 \%)$ of plaques healthy and diseased individuals showing negative results respectively. In the remaining samples from patients, the bacterial numbers were significantly higher than those of healthy subjects with a $\mathrm{p}$ value of $<0.001$ (Fig. 4).

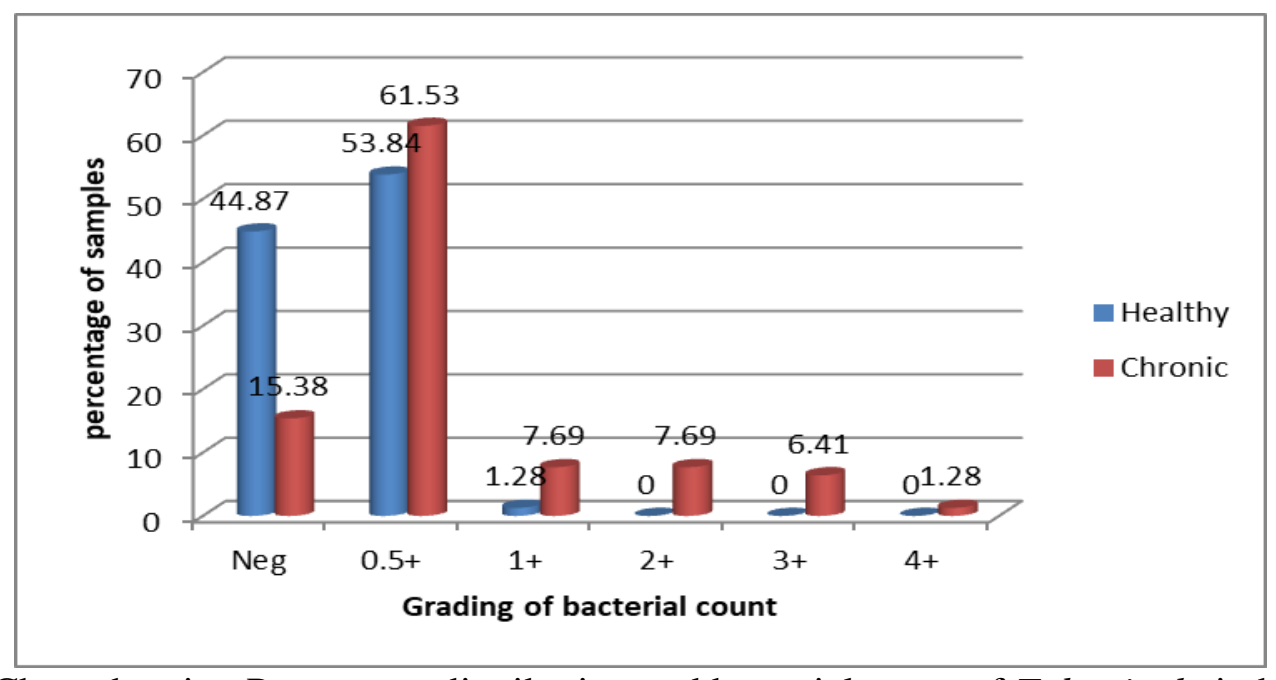

Figure 4: Chart showing Percentage distribution and bacterial count of T.denticola in healthy and chronic samples

When the inter-group ratios were calculated for 25 th, 50th and 75 th percentile expressions, the values were significant for all the three groups (table 2 and 3 ). 
Table 2: Showing percentile distribution of red complex bacteria among healthy individuals and chronic periodontitis patients.

\begin{tabular}{|c|c|c|c|c|c|c|c|c|}
\hline \multirow[b]{2}{*}{ Variable } & \multirow[b]{2}{*}{ Group } & \multirow[b]{2}{*}{$\mathbf{N}$} & \multirow[b]{2}{*}{ Mean } & \multirow[b]{2}{*}{$\begin{array}{l}\text { Std. } \\
\text { Dev. }\end{array}$} & \multicolumn{3}{|c|}{ Percentiles } & \multirow{2}{*}{$\begin{array}{c}\text { Mann-Whitney } \\
\text { test (Z-value, } \\
\text { p-value and } \\
\text { significance) }\end{array}$} \\
\hline & & & & & $25^{\text {th }}$ & $50^{\text {th }}$ & $75^{\text {th }}$ & \\
\hline \multirow[b]{2}{*}{ P.gingivalis } & Healthy & 78 & 0.90 & 0.55 & 0.50 & 1.00 & 1.00 & \multirow{2}{*}{$\begin{array}{c}-4.663 \\
<0.001, \\
\text { Significant }\end{array}$} \\
\hline & $\mathrm{CP}$ & 78 & 1.43 & 0.89 & 1.00 & 1.00 & 2.00 & \\
\hline \multirow[b]{2}{*}{ T.forsythia } & Healthy & 78 & 0.36 & 0.41 & 0.00 & 0.50 & 0.50 & \multirow{2}{*}{$\begin{array}{c}-3.112 \\
0.002, \\
\text { Significant }\end{array}$} \\
\hline & $\mathrm{CP}$ & 78 & 0.68 & 0.72 & 0.50 & 0.50 & 0.50 & \\
\hline \multirow{3}{*}{ T.denticola } & Healthy & 78 & 0.28 & 0.26 & 0.00 & 0.50 & 0.50 & \multirow{3}{*}{$\begin{array}{c}-5.041 \\
<0.001, \\
\text { Significant }\end{array}$} \\
\hline & $\mathrm{CP}$ & 78 & 0.78 & 0.84 & 0.50 & 0.50 & 0.50 & \\
\hline & & & & & & & & \\
\hline
\end{tabular}

Table 3: Showing interbacterial association between red complex bacteria

\begin{tabular}{|c|c|c|c|c|}
\hline & & P.gingivalis & T.forsythia & T.denticola \\
\hline \multirow{3}{*}{ P.gingivalis } & Spearman's Rho & & $.175^{*}$ & $.354^{* *}$ \\
\hline & p-Value & & 0.03 & 0.00 \\
\hline & Significance & & Significant & Significant \\
\hline \multirow{3}{*}{ T.forsythia } & Spearman's Rho & $0.175^{*}$ & \multirow{3}{*}{--} & 0.13 \\
\hline & p-Value & 0.03 & & 0.11 \\
\hline & Significance & Significant & & $\begin{array}{c}\text { Not } \\
\text { significant }\end{array}$ \\
\hline \multicolumn{5}{|c|}{$\begin{array}{l}\text { P.gingivalis Values are significantly and positively correlated T.forsythia as well as } \\
\text { T.denticola values. There was no significant correlation between T.forsythia and } \\
\text { T.denticola. }\end{array}$} \\
\hline
\end{tabular}

Spearman rank correlation coefficient was used to assess the linear relationships between the three red complex bacteria studied. It could be seen that the levels of P. gingivalis correlated significantly with those of T. forsythia and had a p value of 0.03 with Spearman's coefficient of 0.175 (Fig. 5). 


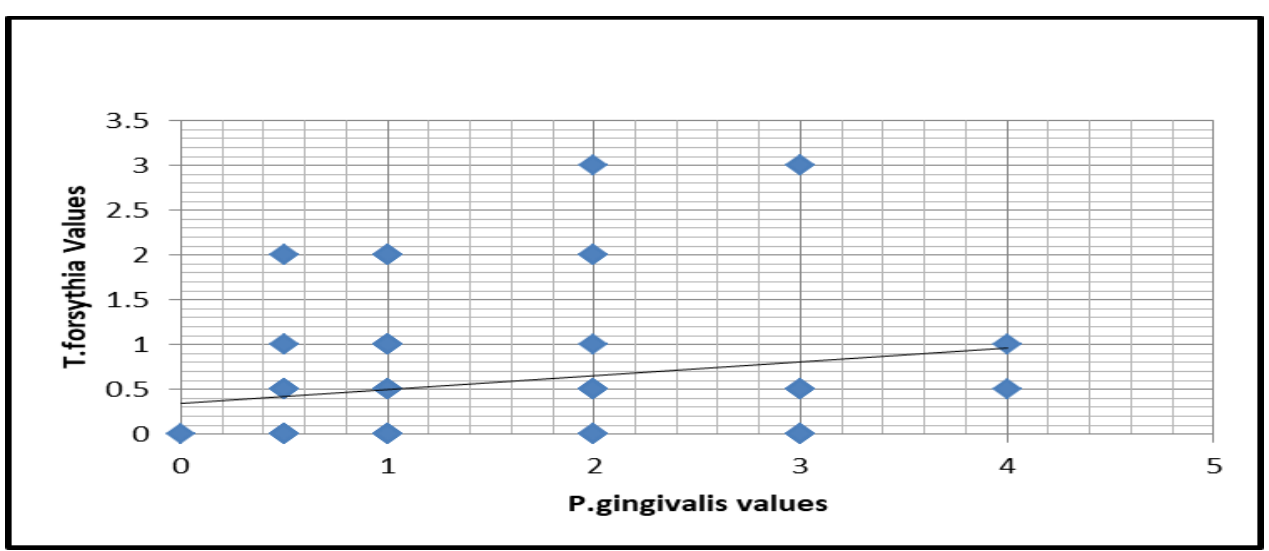

Figure 5: Scatter plot showing relationship between P.gingivalis and T.forsythia values

Similarly, there was a very good linear relationship between P. gingivalis and T. denticola with a $\mathrm{p}$ value of $<0.001$ and Spearman's rho of 0.354 (Fig. 6).

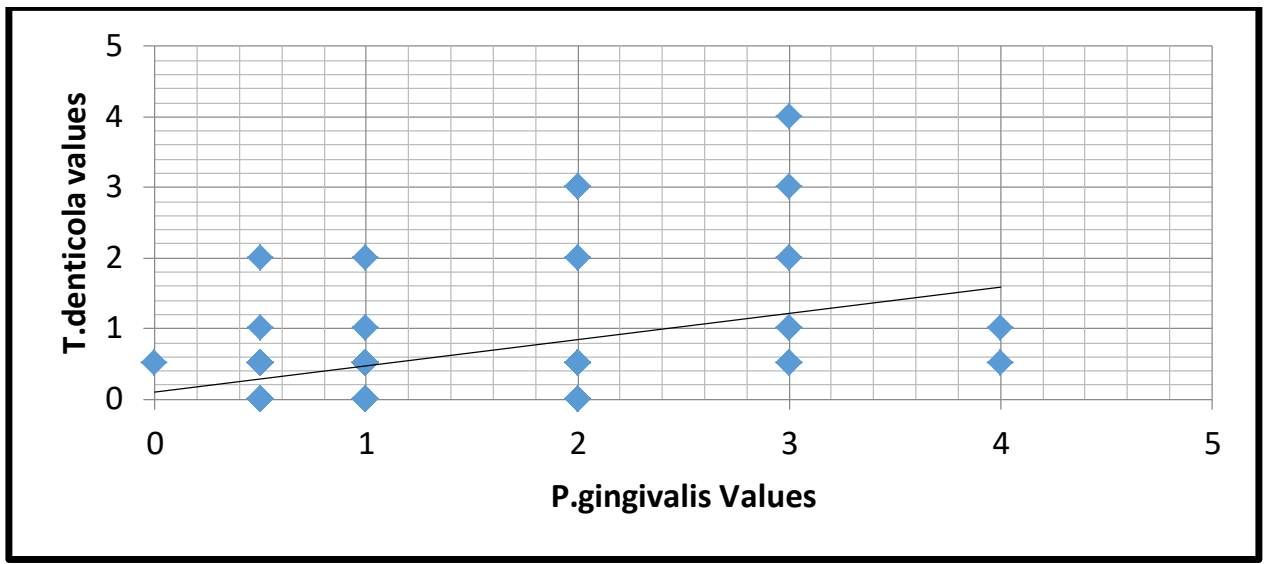

Figure 6: Scatter plot showing relationship between P.gingivalis and T.denticola values

In contrast, we could detect only a weak correlation between $\mathrm{T}$. forsythia and $\mathrm{T}$. denticola levels in the subgingival plaque and the relationship was non-significant with a P value of 0.11 (Fig. 7).

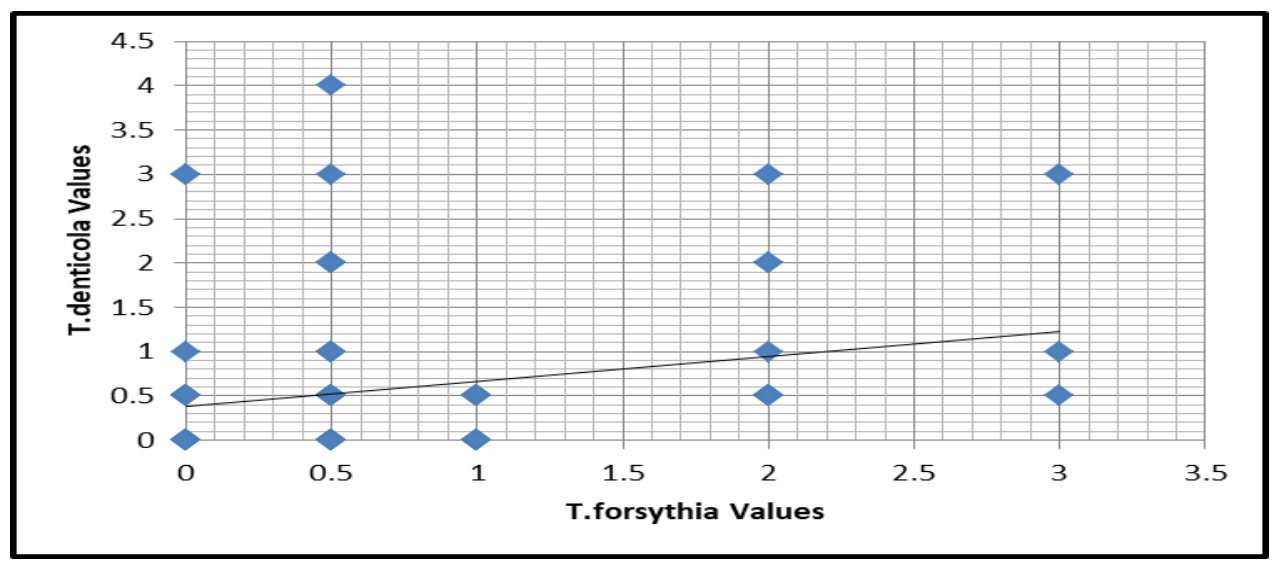

Figure 7: Scatter plot showing relationship between T.denticola and T.forsythia values 
Chronic periodontitis is a polymicrobial infectious disease that results from the overgrowth of a limited number of bacterial species that are members of the oral microflora. Among the various organisms known to be associated with the clinical progression of the disease, 'red complex' which encompasses P. gingivalis, T. forsythia and T. denticola are the most important pathogens of adult periodontitis $[5,10]$. The unifying features of these red complex bacteria are their extracellular proteolytic activity, their ability to utilize amino acid breakdown products for metabolic activity, production of toxic metabolites, outer membrane vesicles and possession of several virulence factors [11]. They are all obligate anaerobes, especially $\mathrm{T}$. denticola and $\mathrm{T}$. forsythia, which are fastidious, have complex nutritional requirements and require several days to few weeks to grow in culture [12]. Hence, a number of culture independent methods such as microscopy, immunological and molecular techniques have been developed over the years to study such difficult to grow oral bacteria. Among them, molecular microbiology techniques are most frequently applied. They can be used as rapid screening tools and serve as important diagnostic approaches in clinical dentistry. However, majority of these techniques are either qualitative indicating the presence or absence of organisms or yield only semi-quantitative results [13]. Among these various techniques, whole cell hybridization with fluorescently labelled 16s rRNA oligonucleotide probes has become very popular. It allows detection of specific bacteria at the single cell level and aid determination of their abundance in complex microbial communities such as dental plaque and results can be easily quantitated [14]. Hence, in the present study, an attempt was made to evaluate the applicability of FISH as a rapid diagnostic tool in patients with periodontitis. The FISH technique provides information about the morphology, number and spatial distribution of various microorganisms in dental plaque. In addition, this method provides direct quantitative results without need for prior culture. The method is rapid, sensitive and can be very specific.

The red complex bacteria are usually not found alone, but in combination in the periodontal pocket suggesting that they exert their action in a co-operative manner to produce clinical disease [15]. Studies using animal models have reported synergistic pathogenicity of mixed infections of $P$. gingivalis with other bacterial species, especially with other members of red complex [10]. These microbes possess numerous potent virulence factors aimed at neutralizing local host defenses and destroying periodontal tissues. But this occurs in only a limited number of individuals harbouring the pathogens, suggesting a complex multifactorial etiology related to an imbalance between host and parasite. These various virulence factors also enable the red complex bacteria to establish synergism and help in their coexistence in subgingival plaque [15$18]$.

The data from our study clearly revealed that $\mathrm{P}$. gingivalis has a very high prevalence in the oral cavity of healthy and periodontally diseased individuals. However, the number of these bacteria is quite low in healthy subjects. In contrast, the prevalence as well as the numbers of T. forsythia and $T$. denticola was significantly lower in healthy subjects when compared to patients with chronic periodontitis. These results are in agreement with several other studies except for the high prevalence of $P$. gingivalis in healthy individuals which we are unable to explain. It is a well-documented fact that the prevalence of periodontal pathogens varies among individuals from different geographical locations and the method used for their detection [5, 19, and 20]. 
Our study also showed a synergistic relationship of $P$. gingivalis with other two bacteria in the subgingival plaque in both the groups. But surprisingly, the association between $T$. forsythia and T. denticola was not significant. The in vivo interactions of these species are still poorly characterized, but some studies have indicated that red complex bacteria are interdependent for them to occur in subgingival plaque [21]. Several studies in patients with chronic periodontitis have shown that red complex bacteria are routinely found together at diseased site in human mouth [22-24]. These bacteria reside at different levels in the periodontal pocket. Using FISH, it has been shown that Tannerella species are located in the intermediate layer of the subgingival plaque whereas $P$. gingivalis is found at the top layer and treponemes are found outside the top layer [25].

It was surprising to note that, despite its popularity in the field of life sciences, FISH has been underutilized in dentistry. Most of the studies are confined to either to study the oral biofilm architecture or to investigate interspecies association. There are very few studies wherein FISH has been used in periodontal disease diagnosis and this study is the first of its kind from India.

\section{Conclusions and Recommendations}

One of the main requirements in periodontal microbiology is to quantify organisms quickly and reliably. This technique which requires just three hours for completion after fixation of the samples can be used as a diagnostic tool for rapid detection and quantitation of oral microbes from clinical samples. Since this method has the ability to detect even a single microbial cell against a mixed background, it can be considered very sensitive and useful for follow up post therapy.

The only limitations of the technique are need for fluorescent microscope which is pretty expensive and availability of expertise to separate the fluorescent stained bacteria from the nonspecific background material. Attempts are being made to improve the specificity of the method still further by either employing probes of a larger length and use of peptide nucleic acids as probes [26]. We feel that the method described here is simple, rapid, and easily adaptable and has great potential for accurate identification of red complex bacteria directly from plaque samples.

\section{Acknowledgements}

We express our sincere gratitude to the advanced research committee, Rajiv Gandhi University of Health Sciences, Bengaluru, Karnataka for funding this project.

\section{References}

[1] Slots J. Periodontology: Past, Present, Perspectives. Periodontol 2000, 62, 2013; 7-19.

[2] Paster BJ, Olsen J, Aas JA, Dewhirst FE. The breadth of bacterial diversity in the human periodontal pocket and other oral sites. Periodontol 2000, 42, 2006; 80-87.

[3] Socransky SS, Haffajee AD, Cugini MA, Smith C, Kent jr RL. Microbial complexes in subgingival plaque. J Clin Periodontol. 25, 1998; 134-144. 
[4] Gmur R, Strub JR, Guggenheim B. Prevalence of Bacteroides forsythus and Bacteroides gingivalis in subgingival plaque of prosthodontically treated patients on short recall. J Periodontol Res. 113, 1989; 113-120.

[5] Holt SC, Ebersole JL. Porphyromonas gingivalis, Treponema denticola and Tanerella forsythia: the 'red complex', a prototype polybacterial consortium in periodontitis. Periodontol 2000, 38, 2005; 72-122.

[6] Paster BJ, Dewhirst FE. Molecular microbial diagnosis. Periodontol 2000, 51, 2009; 38-44.

[7] Amann R, Fuchs BM. Single cell identification in microbial communities by improved fluorescence in situ hybridization techniques. Nature rev. 2008; 339-348.

[8] Klug B, Rodler C, Koller M, Wimmer G, Kessler H, Grube M et al. Oral biofilm analysis of palatal expanders by Fluorescence In-Situ Hybridization and Confocal Laser Scanning Microscopy. J Vis Exp 2011; 56: e2967, DOI: 10.3791/2967.

[9] Greuter D, Loy A, Horn M, Rattie T. Probebase - an online resource for rRNA targeted oligonucleotide probes and primers: new features 2016. Nucl acids res. 44(D1), 2016; D586D589.

[10] Suzuki N, Yoneda M, Hirofugi T. Mixed red-complex bacterial infection in periodontitis. Int J Dent Res 2013; ID: 587279.

[11] Dashper SG, Seers CA, Reynolds EC. Virulence factors of the oral spirochete Treponema denticola. J Dent Res. 90, 2011; 691-703.

[12] Ellen RP, Galimanas VB. spirochetes at the forefront of periodontal infections. Periodontol 2000, 38, 2005; 13-32.

[13] Carrada EA, Scaloni FAR, Cesai OE, Devito KL, Rebeiro LC, Rebeiro RA. Salivary periodontopathic bacteria in children and adolescents with Down syndrome. PLoS ONE 2016; 11: e0162988.

[14] Kenzaka T, Yamaguchi N, Tani K, Nasa M. rRNA targeted FISH analysis of bacterial community structure in river water. Microbiol, 144, 1998; 2085-2093.

[15] Amano A. Host-parasite interactions in periodontitis: Microbial pathogenicity and innate immunity. Periodontol 2000. 54, 2010; 9-14.

[16] Dzink JL, Socransky SS, Haffajee AD. The predominant cultivable microbiota of active and inactive lesions of destructive periodontal diseases. J Clin Periodontol, 15, 1988; 316-323.

[17] Sharma A. Virulence mechanisms of Tannerella forsythia. Periodontol 2000. 54, 2010; 106-116.

[18] Ishihara K. Virulence factors of Treponema denticola. Periodontol 2000, 54, 2010;117-135.

[19] Deng T, Wang I, Jing L, Pang J, Liu B, Du Y et al. Association of three bacterial species and periodontal status in Chinese adults: an epidemiological approach. J Clin Microbiol, 49, 2011; 184-188.

[20] Hajishengallis G, Lammont RJ. Beyond the red complex and into more complexity: the polymicrobial synergy and dysbiosis (PSD) model of periodontal disease etiology. Mol Oral Microbiol, 27, 2012; 409-419.

[21] Sela MN. Role of Treponema denticola in periodontal diseases. Crit Rev Oral Biol Med. 12, 2001; 399-413.

[22] Byrne SJ, Dashper SG, Darby IB, Adams GG, Hoffmann B, Reynolds EC. Progression of chronic periodontitis can be predicted by the levels of Porphyromonas gingivalis and Treponema denticola in subgingival plaque. Oral Microbiol Immunol 2009; 24: 469-477.

[23] Colombo AP, Boches BK, Cotton SL, Goodson JM, Kent R, Haffajee AD et al. Comparison of subgingival microbial profiles of refractory periodontitis, severe periodontitis and periodontal healthusing the human oral microbe. J Perodontol, 80, 2009; 1421-1432.

[24] Mineoka T, Awano S, Kikimaru T, Kurata H, Yoshida A, Ansari T et al. Site specific development of periodontal disease is associated with increased levels of Porphyromonas gingivalis, Treponema denticola and Tannerella forsythia in subgingival plaque. J Periodontol. 79, 2008; 670-676. 
[25] Zinge V, Barbara M, van Leeuwen M, Degener JE, Abbas P, Thurnheer T et al. Oral biofilm architecture on natural teeth. PLoS One 2010; 5(2): e9321.

[26] Mendes L, Rocha R, Azevedo AS, Ferriera C, Henriques M, Pinto MG et al. Novel strategy to detect and locate periodontal pathogens: the PNA-FISH technique. Microbiol Res. 192, 2016; 185-191.

*Corresponding author.
E-mail address: drkgbhat@ yahoo.com 